\title{
The dynamics of social deprivation in Mexico
}

1 Economic Studies Department, El Colegio de la Frontera Norte, Tijuana, Mexico, jcramirez@ colef.mx

2 Anahuac-Mexico-Norte University, vivian.kadelbach@anahuac.mx.

3 Anahuac-Mexico-Norte University. Corresponding author: leovardo.mata@anahuac.mx

\begin{abstract}
This paper aims to model the dynamics of social deprivation in Mexico using a Markovian approach. First, we establish a scenario where a list of items characterizing social deprivation evolves as a first-order Markov chain under the sample period (2002-2012). Then, we estimate latent states and ergodic vectors of a hidden-Markov model to verify the strength of the conclusions drawn from such a scenario. After collecting results from both kinds of analyses, we find a similar pattern of impoverishment. The paper's conclusions state that the evolution of Mexico's deprivation profile may slightly worsen soon.
\end{abstract}

JEL Classification: C15, I32

Keywords: Hidden and direct Markov models, Mexico's social deprivation, poverty profile, latent states, ergodic vectors. 


\section{Introduction}

A growing number of authors uses the material deprivation approach as an alternative to income or consumption methods to identify the poor (Watson et al., 2017; Dotto et al., 2018). Its multidimensional nature makes it a more direct and complete instrument to measure poverty because, far from relying on a single variable (income), it emphasizes the combination of functioning failures regarding material living conditions (Sen 1981). The measures based on the material deprivation method, whether they follow the counting or welfare approaches, seek to obtain a deprivation score from a list of items to which weights are associated. If the number of that score is lower or higher than a threshold constructed with numerical or categorical scales, people are classified as poor or non-poor (Whelan and Maître 2007). In dynamic studies, thresholds are also employed to differentiate transitory from chronic poverty, as well as to determine factors that delay (such as individuals' history of poverty) or speed up (such as improvements in income) the times of entry or exit of people in different states of deprivation (ㅅranz and Cantó 2012; Ayllón 2013).

A relevant aspect of this literature is the study of poverty with latent models using longitudinal surveys. Primarily in this category are the Markov models, whose application relies on assuming that society's heterogeneity is challenging to discover with manifest variables. According to some proponents, the dynamics of social heterogeneity is only possible to analyze by constructing latent variables drawn from lists of items that play the role of manifest variables (Whelan and Maitre 2006; Najera 2017). Latent variables are underlying poverty categories that differentiate between disadvantaged and non-disadvantaged populations or any other optional classification. The procedure adopted requires implementing a hidden Markov model (HMM) guided by a process parameter, which calculates the optimal number of latent states and the state-dependent probabilities. The process parameter may be associated with a particular probability distribution, a heuristic method, or an activation function of a neural network. Each of these steps involves significant methodological issues ranging from the proper delimitation of the list of items to attrition problems (Dotto et al., 2018).

This document also extracts latent states from a list of items to understand the poor Mexican population's deprivation dynamics. However, unlike previous studies, identifying those states is not an intermediate step to construct material deprivation scores or calculate chronic and transitory poverty, but to study the long-term behavior of the transition probabilities of Mexico's social deprivation. Specifically, the paper aims to determine the stationary probabilities of exposure to social deprivation to provide a future profile of the Mexican population's impoverishment conditions. In this sense, results from this document complement those of the studies above-mentioned as they can serve as an input for poverty measurements that apply ergodicity criteria.

In the process of identifying latent states, we use direct and hidden Markov models (the latter driven by a binomial process), whose state spaces include ten deprivals associated with a list containing the same number of items. This list comes from the Oxford Poverty and Human Development Initiative (OPHI 2015). It consists of ten manifest variables or items, which are more social than material (hence we decide to use the term social deprivals, or SD for short, instead of material deprivals). A social deprival arises when an individual does not meet the minimum requirements associated with the criteria of each item described by OPHI in Alkire et al. (2020). The poor can accumulate, then, up to a maximum of ten deprivals. As we are interested in the number of deprivals and not using a weighting scheme to construct a poverty index, each deprival has the same weight. The Mexican Family Life Survey or ENNVIH (UIA, CIDE, and Duke University, 2016) provides each item's information from 2002-2012.

This paper's main finding is that, in the absence of events that modify the present transition probability structure, the country may soon experience worsening deprivation conditions. In other words, the probability of turning moderate poor into extreme poor can be slightly more significant in the short term. This conclusion goes against studies that propose exit times from 
poverty under certain conditions of growth of the gross domestic product (GDP). The statistical analysis developed here establishes that some transition probabilities are insensitive to GDP growth rates because they also depend on aspects linked to income distribution mechanisms or social factors.

The document has five additional sections. The second explains how we model the probability of experiencing social deprivation as a Markov chain and highlights the importance of combining different approaches. The third section addresses some methodological issues on data treatment. The fourth section develops the procedure to obtain the direct approach's observable transition probabilities and the ergodic vectors. The fifth section expands the previous analysis by applying hidden Markov models (HMM) to discover the original data's underlying structure through latent states. The sixth section briefly discusses the results in the context of Mexico's current economic and social conditions. The conclusions summarize the key findings.

\section{The probability of experiencing social deprivation as a Markov chain}

The direct approach

An important starting point of this paper is to consider the random variable $X: \Omega \rightarrow \Re$ as the exposure to social deprivation, which maps the number of events of the sample space $\Omega=\left\{X_{1}, \ldots, X_{m}\right\}$ into some discrete points of the real line $\mathfrak{R}$. Specifically, $X=\sum_{i=1}^{m} X_{i}$, where $X_{i}$ is equal to one when a household experiences the deprival $\boldsymbol{i}$ and zero otherwise. The set of $m=10$ deprivals is defined according to Alkire et al. (2020) in the following three dimensions: Education (1. Years of Schooling and 2. School Attendance); Health (3. Child Mortality, and 4. Nutrition) and Standard of Living (5. Electricity, 6. Sanitation, 7. Water, 8. Flooring, 9. Fuel and 10. Assets).

To preserve the event structure over time, we assume that $X^{-1}(B) \in \mathfrak{I}$ where $B$ is a Borel subset on $\mathfrak{R}$ and $\mathfrak{I}$ is a sigma field consisting of all possible combinations of the elements of $\Omega$. Since no household in the survey is free from deprivation over the entire period, then each subset $B$ is a non-empty set such that $X^{-1}(0) \notin \mathfrak{I}$. Regarding this last point, it should be noted that although 746 people interviewed declared not being vulnerable or deprived at the beginning of the survey, all of them reported at least one deprival in the subsequent waves (excluding those households eliminated due to intermittent information problems). Therefore, we decided to remove the zero deprivation event from the study because the cohort's empirical transition probabilities of not experiencing deprivation between 2002 and 2012 are zero. We will return to this point later.

To model the dynamics of $\boldsymbol{X}$, we use a stochastic, discretely indexed process consisting of a family of random variables $\boldsymbol{X}_{\boldsymbol{t}}, t=0,1,2, \ldots, T$, as defined above, with a finite number of states $\boldsymbol{s}_{i}, i=1,2 \ldots, N ; \mathrm{N} \leq m$. The number of states depends on the $m=10$ deprivals (not on the three dimensions) and other criteria based on CONEVAL (2016), which we will discuss below. In particular, we adopt a one-step homogeneous Markov chain $\left\{C_{t}\right\}$ with a discrete state space $E=\left\{s_{i}\right\}$ because its two assumptions appropriately fit the paper's aim. The two assumptions allow us to find the future probabilities of exposure to deprivation from the present deprivation conditions (equation 1), provided that Mexico's economic situation is such that the present probability structure remains unchanged (equation 2).

$$
\begin{gathered}
P\left[X_{t}=s_{j} \mid X_{\mathrm{t}-1}=s_{i}, X_{t-2}=s_{k}, \ldots,\right]=P\left[X_{t}=s_{j} \mid X_{\mathrm{t}-1}=s_{i}\right] \\
P\left[X_{t}=s_{j} \mid X_{0}=s_{i}\right]=P\left[X_{t}=s_{j} \mid X_{\mathrm{t}-1}=s_{i}\right] \\
\quad \text { for each } t \in\{0,1,2, \ldots, T\} \text { and } i, j \in\{1,2, \ldots N\} .
\end{gathered}
$$


The direct approach only requires the initial conditions (a probability density function for $\boldsymbol{X}_{\boldsymbol{0}}$ ) and the one-step transition probabilities $\boldsymbol{g}_{i j}$ to characterize the stochastic process dynamics, so that:

$$
\begin{gathered}
P\left[X_{0}=x_{0}, X_{1}=x_{1}, \ldots, X_{T}=x_{T}\right]=P\left[X_{0}=x_{0}\right] \prod_{t=1}^{T} P\left[X_{t}=x_{t} \mid X_{t-1}=x_{t-1}\right] \\
\gamma_{i j}=P\left[X_{t}=s_{j} \mid X_{t-1}=s_{i}\right]
\end{gathered}
$$

for eacht $\in\{0,1,2, \ldots, T\}$. The set of probabilities $\boldsymbol{g}_{i j}$ allows defining a Markov matrix $\Gamma$ of $N \times N$ with $0 \leq \gamma_{i j} \leq 1$ and $\sum_{j=1}^{N} \gamma_{i j}=1, i=1,2, \ldots, N$.

The convergence conditions of $\Gamma$ vary according to the nature of the chain, number, and periodicity of the final classes. If the chain has only one final class, consisting of an irreducible state space, aperiodic and without transient classes, then the chain is regular and ergodic with a unique steady-state probability vector $\delta=\left(\delta_{1}, \delta_{2}, \ldots, \delta_{N}\right)$ where

$$
\delta_{j}=\lim _{t \rightarrow \infty} \gamma_{i j}(t) i, j \in\{1,2, \ldots N\}
$$

If, conversely, the chain is semi-ergodic, non-ergodic, semi-regular, poly-cyclical, or mixed, the calculation of steady-state or ergodic probability matrices becomes more complicated (for further details, see Feldman and Valdez 1996).

\section{The hidden approach}

When estimating the ergodic vector with the direct approach, one must assume the initial structure of transition probabilities and states' numbers. The problem arises when the assumed probabilities and states do not match the sample data's underlying structure. Do results from the ergodic vector still hold to be valid and robust?

The answer to this critical question is at the heart of the HMM. In these models, both states and transition probabilities are the variables to determine. They need to be found assuming that latent states follow a Markov chain in which the current state thoroughly explains the probability distribution of observations at any time. This process of discovery involves two probabilistic mechanisms. Firstly, an unobserved $\left\{C_{t}\right\}$ with (5) as its initial probability distribution; and secondly a set of probability distributions, one for each state $\boldsymbol{s}_{\boldsymbol{i}}$ that produce the observations from a finite set of N possibilities (Mac Donald and Zucchini 1997).

The resulting stochastic process of both mechanisms is an integer-valued random sequence $\left\{S_{t}: t=0,1,2, \ldots, T\right\}$ that conditionally on $C^{(T)}=\left\{C_{t}: t=0,1,2, \ldots, T\right\}$ is mutually independent. In this process, $S_{t}$ takes the value $j$ with probability ${ }_{t} \pi_{i j}$ if $C_{t}=i$, depending on the conditional distribution of $S_{t}$. As we choose the binomial distribution to fit the likelihood of having a certain number of deprivals (success) or not (failure), then the state-dependent-probabilities $t \pi_{i j}$ are expressed as

$$
P\left(S_{t}=j \mid C_{t}=i\right)={ }_{t} \pi_{i j}=\left(\begin{array}{c}
N \\
j
\end{array}\right) p_{k}^{j}\left(1-p_{k}\right)^{N-j}
$$

where $\boldsymbol{p}_{\boldsymbol{k}}$ is the probability of success for deprivation $k=1,2, \ldots, m$.

Once set the previous conditions, the next step is to get the hidden states and the state-dependent probabilities matrix $\Pi$ by implementing a calculation procedure for the binomial distribution parameters $p_{k}(k=1,2, \ldots, m)$. This procedure depends on the set of observations $x=\left(x_{0}, x_{1}, \ldots, x_{T}\right)$ and on a given number of states $N$. We use the expectation-maximization 
(EM) algorithm that maximizes the following conditional pseudo-log-likelihood function for $i=1,2, \ldots, N$ :

$$
l_{T}=\sum_{t=1}^{T} \ln \left[P\left(S_{t}=s \mid C_{t}=i\right)\right]
$$

The algorithm yields the vector of parameters $\theta=\left(p_{1}, p_{2}, \ldots, p_{N}\right)$ by iteratively maximizing the expected joint log-likelihood and taking $\hat{p}_{k}=0.5$ as the starting point de calculation process, as suggested by Mac Donald and Zucchini (1997). After getting the parameters $\hat{\theta}^{*}=\left(\hat{p}_{1}, \hat{p}_{2}, \ldots, \hat{p}_{N}\right)$ with $(7)$, the EM algorithm finds the hidden states $\widehat{N}^{*}, \Pi$, and the stationary vectors by using information criteria. The statistical analysis is run in the $\mathrm{R}$ library for Markov chains (https://cran.r-project.org/web/packages/depmixS4/index.html).

\section{Why is an integrated Markovian approach useful in understanding the dynam- ics of social deprivation in Mexico?}

This paper's primary contribution is to combine both approaches to offer a comprehensive dynamic vision on SD that, to our best knowledge, is unprecedented in the literature on poverty in Mexico. One reason is that results from both stochastic processes complement each other. One gives information that the other does not provide and vice versa. For instance, HMM captures over-dispersion and serial dependence that is not possible to get utilizing direct Markov chains. In this sense, the first models produce more realistic stationary probabilities than those of the last ones as HMM allow the construction of matrices with different means and variances. However, the direct approach is also a valuable tool to validate the assumptions needed by HMM. By testing ergodicity in observed matrices with the direct approach, one can guarantee HMM's acceptable use. Otherwise, latent states or stationary hidden matrices would be meaningless. Therefore, we use the two stochastic processes to reach robust conclusions on the underlying data structure.

A second reason is that calculating stationary probabilities with both approaches helps validate the realism of the hypotheses associated with long-term poverty behaviors in a double-check process. As observed probability matrices consider real initial economic and social conditions, they become useful tools to weigh the reliability of future scenarios built by HMM that assume automatic responses of poverty to variations in GDP growth rates (poverty reduction) or no reactions from deprivals to economic changes (poverty traps).

\section{Data source and methodological issues}

For the combined approach to be applied correctly, it is necessary to collect specific longitudinal information and verify that SD behave as a Markov chain. This section will focus on the first condition and leave the second for the next section.

The source of information used in this paper comes from ENNVIH, a multi-thematic panel survey whose longitudinal nature allows analyzing the conditions of deprivation in the country over time. It initially collects information at the household and community levels of a sample of 35,677 individuals, 8,441 households, 16 entities, and 150 communities in three waves at different points in time $(2002,2005-2006,2009-2012)$. The household report splits into individual and family data, while community information refers to schools, health services, and the observed community's general characteristics. The survey considers the following five regions: 
- Region 1 (South/Southeast): Oaxaca, Veracruz, and Yucatán

- Region 2 (Center): Distrito Federal, Estado de México, Morelos, and Puebla

- Region 3 (Center/West): Guanajuato, Jalisco, and Michoacán

- Region 4 (Northwest): Baja California Sur, Sinaloa, and Sonora

- Region 5 (Northeast): Coahuila, Durango and Nuevo León

How this information is organized is beneficial for our purposes because it enables us to build the cohort of households critical to conducting a Markovian analysis. As explained in Rubalcava and Teruel (2013), the three waves of ENNVIH focus on the baseline households of the 2002 panel, so members' losses or gains are considered adjustments experienced by those households over time. These adjustments help resolve some of the attrition problems related to longitudinal surveys.

Despite this virtue, ENNVIH data still presents problems of sample representativeness. With a re-contact rate of $90 \%$ for the subsequent waves, the survey cannot interview all the same households over time. Therefore, we select only those households of 2002 whose folio numbers continued to exist in the two subsequent waves to balance the panel.

The selection procedure involves monitoring the household members during the different waves and eliminating those units without continuous information. Monitoring consists of following the movements of household members to the USA or other places of Mexico, based on socio-demographic criteria, to identify them and estimate their deprivals throughout the sample period properly. If this follow-up finds that any member is untraceable or that answers to questionnaires are inconsistent over time, the sample is shortened. Eliminating households whose members' responses to questionnaires are inexistent or incomplete affects both deprived and non-deprived populations. It appears that due to their smaller sample size, the non-disadvantaged households are the least represented group in the survey due to the non-response rate. However, this is not the case as this group also experienced a real process of impoverishment: 300 out of 746 households without deprivation in 2002 had at least one deprivation in the second wave. These kinds of reasons led us to restrict the analysis to households with at least one deprivation. Table 1 shows the final figures for households (6787) that form the cohort of survivors exposed to the same SD group during the entire sample period.

In addition to this correction, we made the sample periods equidistant using cubic spline interpolation. We interpolate the number of surviving households between 2002 and 2012 as if their number of deprivals were yearly averages of the survey's contiguous periods. To identify the mid-points of the interpolation, especially in the 2009-2012 wave, we fix the specific time the survey takes place using survey data (age of the interviewed, birthday, and number of folios). Formally, those averages are estimates of a cubic spline polynomial $\boldsymbol{S}(x)$ for each household on the sub-intervals $\left[x_{j}, x_{j+1}\right], j=0,1, \ldots, n-1$, according to the following conditions:

a. $S_{j}\left(x_{j}\right)=f\left(x_{j}\right)$ y $S_{j}\left(x_{j+1}\right)=f\left(x_{j+1}\right)$ for every $j=0,1, \ldots, n-1$.

b. $S_{j+1}^{\prime}\left(x_{j+1}\right)=S^{\prime}{ }_{j}\left(x_{j+1}\right)$ for every $j=0,1, \ldots, n-1$.

c. $\quad S^{\prime \prime}{ }_{j+1}\left(x_{j+1}\right)=S^{\prime \prime}{ }_{j}\left(x_{j+1}\right)$ for every $j=0,1, \ldots, n-1$.

d. $S^{\prime \prime}\left(x_{0}\right)=S^{\prime \prime}\left(x_{n}\right)=0$ 
The sub-intervals $\left[x_{j}, x_{j+1}\right]$ are partitions of the domain of $x$ on the closed set $2002=a \leq x_{0}<x_{1}<\cdots<x_{N} \leq b=2012$, whose corresponding images yield $N+1$ points $\left(x_{0}, y_{0}\right),\left(x_{1}, y_{1}\right), \ldots,\left(x_{N}, y_{N}\right)$ over the curve $y=f(x)$, This curve describes the households' deprivals for each year between 2002 and 2012.

Table 1. Number of sample units by periods

\begin{tabular}{lll}
\hline Year & & Observations \\
\cline { 3 - 3 } & $\begin{array}{ll}\text { Sample in ENNVIH } \\
\text { (Households) }\end{array}$ & Re-contact (90\%) \\
2002 & $8,441(35,677)$ & \\
$2005-2006$ & $8,437(38,223)$ & $7,572(32,109)$ \\
$2009-2012$ & $10,125(46,342)$ & $6,787(28,898)$ \\
\hline
\end{tabular}

Note. Numbers in parentheses are individuals.

Source: Authors, based on UIA, CIDE, and Duke University (2016).

We chose two midpoints (2004 and 2008) and one extreme point (2012) on the curve as the new equidistant sample periods to minimize interpolation biases. Table 2 displays the number of households in the new sample points. The three states are defined to adjust CONEVAL's poverty classification (CONEVAL 2016): (i) people with one or more deprivals and income level above the minimum welfare line (lacking population), (ii) people with three or fewer deprivals and income level below the minimum welfare line (moderate poor), and (iii) people with more than three deprivals and income level below the minimum welfare line (extreme poor). Data on incomes linked to minimum welfare lines come from CONEVAL (2016),

Table 2 reveals an initial families' transfers among states and then a relative stabilization. The outcome is a very slight decrease in the number of lacking and extremely poor households, mainly derived from an income improvement between 2004 and 2008, and a sustained increase in the number of moderate poor after the international crisis of 2008-2009 (see Székely and Ortega 2014).

These exchanges are unevenly distributed among families as we move from state 1 to state 2 but not from state 2 to 3 . Table 3 presents the descriptive statistics considering the new equidistant sample periods for the three states. The last row of Table 3 shows that Pearson's bounded coefficients of variation increase with the total mean of state 2 (2.72 deprivals) to then increase with the mean of state 3 (5.67 deprivals) (for an interpretation of these coefficients, see Weisberg 1986). The reason is due to the higher dispersion of family transfers to state 2 than to state 3 . The changes in the latter state were not so significant as those that occurred in state 2.

Table 2. Number of surviving households by states of deprivation

\begin{tabular}{ccc}
\hline Year & State & Households \\
\hline 2004 & 1 & 1,845 \\
& 2 & 1,555 \\
& 3 & 3,387
\end{tabular}

1,807

$2 \quad 1,661$


Table 2. (continued). Number of surviving households by states of deprivation

\begin{tabular}{ccc}
\hline Year & State & Households \\
\hline & 3 & 3,319 \\
2012 & & \\
& 1 & 1,811 \\
& 2 & 1,673 \\
& 3 & 3,303 \\
\hline
\end{tabular}

Source: Authors, based on UIA, CIDE, and Duke University (2016).

Table 3. Pearson's bounded coefficients of variation (BCV) and other descriptive statistics on Mexico's social deprivals for the sample period 2004-2012

\begin{tabular}{|c|c|c|c|c|c|c|c|c|c|c|}
\hline \multicolumn{11}{|c|}{ ENNVIH 2004-2012 } \\
\hline \multirow[b]{2}{*}{ Deprivation } & \multicolumn{5}{|c|}{ State 1} & \multicolumn{5}{|c|}{ State 2} \\
\hline & Mean & $\begin{array}{l}\text { Stan- } \\
\text { dard } \\
\text { Devia- } \\
\text { tion }\end{array}$ & $\mathrm{BCV}$ & $\begin{array}{l}\text { Skew- } \\
\text { ness }\end{array}$ & Kurtosis & Mean & $\begin{array}{l}\text { Stan- } \\
\text { dard } \\
\text { Devia- } \\
\text { tion }\end{array}$ & $\mathrm{BCV}$ & $\begin{array}{l}\text { Skew- } \\
\text { ness }\end{array}$ & Kurtosis \\
\hline $\begin{array}{l}\text { Years of Schoo- } \\
\text { ling }\end{array}$ & 0.26 & 0.44 & 0.46 & 1.07 & 2.16 & 0.25 & 0.43 & 0.47 & 1.17 & 2.39 \\
\hline $\begin{array}{l}\text { School Atten- } \\
\text { dance }\end{array}$ & 0.26 & 0.24 & 0.29 & 0.87 & 2.58 & 0.30 & 0.21 & 0.23 & 1.19 & 2.21 \\
\hline Nutrition & 0.36 & 0.38 & 0.40 & 0.47 & 1.48 & 0.33 & 0.44 & 0.48 & 0.92 & 1.55 \\
\hline Child Mortality & 0.01 & 0.11 & 0.12 & 1.83 & 4.14 & 0.02 & 0.14 & 0.15 & 2.30 & 3.30 \\
\hline Cooking Fuel & 0.20 & 0.40 & 0.42 & 1.53 & 3.35 & 0.32 & 0.46 & 0.50 & 0.79 & 1.64 \\
\hline Sanitation & 0.08 & 0.26 & 0.28 & 3.21 & 8.05 & 0.10 & 0.30 & 0.33 & 2.54 & 4.83 \\
\hline Water & 0.95 & 0.08 & 0.09 & -8.43 & 10.47 & 0.92 & 0.08 & 0.09 & -6.83 & 10.30 \\
\hline Electricity & 0.03 & 0.17 & 0.18 & 5.51 & 9.66 & 0.03 & 0.17 & 0.18 & 5.72 & 7.07 \\
\hline Flooring & 0.04 & 0.20 & 0.22 & 4.19 & 10.78 & 0.07 & 0.25 & 0.28 & 3.38 & 7.79 \\
\hline Asset Ownership & 0.80 & 0.40 & 0.42 & -1.47 & 3.16 & 0.77 & 0.41 & 0.45 & -1.34 & 2.90 \\
\hline Total & 2.49 & 0.91 & 0.21 & 0.88 & 4.38 & 2.72 & 0.77 & 0.37 & 0.95 & 2.91 \\
\hline
\end{tabular}

\section{State 3}

\begin{tabular}{|c|c|c|c|c|c|}
\hline \multirow[b]{2}{*}{ Deprivation } & \\
\hline & Mean & $\begin{array}{l}\text { Stan- } \\
\text { dard } \\
\text { Devia- } \\
\text { tion }\end{array}$ & BCV & $\begin{array}{l}\text { Skew- } \\
\text { ness }\end{array}$ & Kurtosis \\
\hline
\end{tabular}

\begin{tabular}{lccccc}
\hline $\begin{array}{l}\text { Years of Schoo- } \\
\text { ling }\end{array}$ & 0.30 & 0.46 & 0.48 & 0.86 & 1.74 \\
\hline $\begin{array}{l}\text { School Atten- } \\
\text { dance }\end{array}$ & 0.28 & 0.21 & 0.26 & 0.74 & 2.29 \\
\hline
\end{tabular}


Table 3. (continued). Pearson's bounded coefficients of variation (BCV) and other descriptive statistics on Mexico's social deprivals for the sample period 2004-2012

\begin{tabular}{|c|c|c|c|c|c|}
\hline \multirow[b]{2}{*}{ Deprivation } & \multicolumn{5}{|c|}{ State 3} \\
\hline & Mean & $\begin{array}{l}\text { Stan- } \\
\text { dard } \\
\text { Devia- } \\
\text { tion }\end{array}$ & BCV & $\begin{array}{l}\text { Skew- } \\
\text { ness }\end{array}$ & Kurtosis \\
\hline
\end{tabular}

\begin{tabular}{llllll}
\hline Nutrition & 0.55 & 0.48 & 0.52 & -0.21 & 1.13 \\
\hline Child Mortality & 0.01 & 0.11 & 0.12 & 1.30 & 5.64 \\
\hline Cooking Fuel & 0.40 & 0.49 & 0.50 & 0.39 & 1.16 \\
\hline Sanitation & 0.14 & 0.35 & 0.35 & 2.05 & 3.21 \\
\hline Water & 0.93 & 0.10 & 0.10 & -6.25 & 10.22 \\
\hline Electricity & 0.03 & 0.18 & 0.19 & 5.19 & 8.97 \\
\hline Flooring & 0.09 & 0.28 & 0.27 & 2.95 & 9.40 \\
\hline Asset Ownership & 0.85 & 0.34 & 0.40 & -1.95 & 4.93 \\
\hline Total & 5.67 & 0.99 & 0.34 & 0.91 & 3.49 \\
\hline
\end{tabular}

Source: Authors, based on UIA, CIDE, and Duke University (2016).

The interesting point of this last fact is that data for families in state 2 have a more rightskewed distribution (0.95) than in states $1(0.88)$ and $3(0.91)$. This distributional characteristic means that child mortality, for example, is higher than the sample mean in state 2 because its skewness value (2.30) is significantly larger than in states 1 (1.83) and 3 (1.30). For other deprivals such as water, where data distibution is left-skewed, the conclusion is ambiguous because the kurtosis of its distribution (10.3 in state 2) indicates that many outliers are experiencing that deprival (fat-tailed distribution).

\section{The dynamics of Mexico's social deprivations using observable Markov chains.}

The second condition for a correct application of the proposed approach is to verify that SD evolve as a Markov chain. The procedure to demonstrate it involves calculating the transition probabilities $\boldsymbol{g}_{i j}$ from equation (4) and a test of goodness of fit for the observed and estimated Markov matrices $\Gamma$. The results shown in Table 4 are obtained using the R library for Markov chains https://cran.r-project.org/web/packages/depmixS4/index.html.

The left side of Table 4 displays the observed probabilities $\boldsymbol{g}_{i j}$, the calculations of which involve maximum likelihood methods (see Lee et al. 1970; Pelzer 2001). These probabilities show a weak tendency for the population to remain in the same state and a greater probability of migrating to states with a more significant number of deprivals. In particular, the observed Markov chain makes it clear that i) the tendency is more evident in state 2, and ii) a Mexican family is more likely to be extremely poor than lacking since the probability of passing from state 1 to state 3 is more significant than in the opposite direction.

The right side of Table 4 presents the estimated $\boldsymbol{g}_{i j}$, which result from iterating the observed matrix once. These new transition probabilities represent the theoretical future values $\boldsymbol{g}_{i j}$ when the observed probabilities follow a one-step Markov chain dynamic (2004-2012). If these probabilities reproduce the same pattern described as the observed $\boldsymbol{g}_{i j}$, then the Markov model fit is 
adequate. Since all the entries on both sides of Table 4 have similar probability distributions, we can conclude that SD behave as a one-step Markov chain. The null hypothesis $\left(\boldsymbol{H}_{\boldsymbol{0}} \mathrm{SD}\right.$ fit a Markov chain pattern) prevails with a value of $p=0.1159$, considering a $95 \%$ confidence interval.

Table 4. Transition probabilities of social deprivation in Mexico, 2004-2012.

\begin{tabular}{|c|c|c|c|c|c|c|c|}
\hline States & 1 & 2 & 3 & States & 1 & 2 & 3 \\
\hline & 0.2770 & 0.2101 & 0.5129 & & 0.2672 & 0.2422 & 0.4906 \\
\hline 1 & $\begin{array}{l}(0.1179, \\
0.4361)\end{array}$ & $\begin{array}{l}(0.0511, \\
0.3692)\end{array}$ & $\begin{array}{l}(0.3538, \\
0.6720)\end{array}$ & 1 & $\begin{array}{l}(0.1304, \\
0.4039)\end{array}$ & $\begin{array}{l}(0.1054, \\
0.3789)\end{array}$ & $\begin{array}{l}(0.3538, \\
0.6274)\end{array}$ \\
\hline & 0.3438 & 0.2793 & 0.3769 & & 0.2735 & 0.2556 & 0.4710 \\
\hline 2 & $\begin{array}{l}(0.2340 \\
0.3936)\end{array}$ & $\begin{array}{l}(0.2295, \\
0.3288)\end{array}$ & $\begin{array}{l}(0.3273, \\
0.4265)\end{array}$ & 2 & $\begin{array}{l}(0.1539 \\
0.3931)\end{array}$ & $\begin{array}{l}(0.1361 \\
0.3751)\end{array}$ & $\begin{array}{l}(0.3515, \\
0.5905)\end{array}$ \\
\hline & 0.2974 & 0.2145 & 0.4881 & & 0.2635 & 0.2447 & 0.4917 \\
\hline 3 & $\begin{array}{l}(0.1571, \\
0.4378)\end{array}$ & $\begin{array}{l}(0.0742, \\
0.3548)\end{array}$ & $\begin{array}{l}(0.3481 \\
0.6286)\end{array}$ & 3 & $\begin{array}{l}(0.1261 \\
0.4011)\end{array}$ & $\begin{array}{l}(0.1156 \\
0.3822)\end{array}$ & $\begin{array}{l}(0.3542, \\
0.6292)\end{array}$ \\
\hline
\end{tabular}

Statistic $\chi^{2}=\mathbf{4 . 3 9} \quad$ p-value $=0.1159$

Note: Numbers in round brackets are $95 \%$ simultaneous confidence intervals.

Source: Authors

\section{Probabilities adjusted for the GDP growth rate}

To make the analysis more realistic, we measure the marginal effect of those probabilities to a variation of the real GDP growth rate. The idea is to explore how sensitive the transition probabilities to changes in the economic environment are. To this end, we run a multi logit model for each state of the Markov chain $i=1,2, \ldots, N$, where the independent variable is the annual real GDP growth rate for the 16 entities included in the ENNVIH, and the dependent variables $\boldsymbol{D}_{\boldsymbol{i}}$ takes the values one, two, and three depending on the transitions from state $\boldsymbol{i}$ to state $\boldsymbol{j}$, as follows:

$$
D_{1}=\left\{\begin{array}{l}
1 \text { if } s_{t-1}=1 \text { and } s_{t}=1 \\
2 \text { if } s_{t-1}=1 \text { and } s_{t}=2 \\
3 \quad \text { if } s_{t-1}=1 \text { and } s_{t}=3
\end{array}\right.
$$




$$
\begin{aligned}
& D_{2}= \begin{cases}1 & \text { if } s_{t-1}=2 \text { and } s_{t}=1 \\
2 & \text { if } s_{t-1}=2 \text { and } s_{t}=2 \\
3 & \text { if } s_{t-1}=2 \text { and } s_{t}=3\end{cases} \\
& D_{3}= \begin{cases}1 & \text { if } s_{t-1}=3 \text { and } s_{t}=1 \\
2 & \text { if } s_{t-1}=3 \text { and } s_{t}=2 \\
3 & \text { if } s_{t-1}=3 \text { and } s_{t}=3\end{cases}
\end{aligned}
$$

The statistical analysis includes control variables (zone of residence and type of Region) and dummies for the sample years. Formally, the conditional probability $P\left[D_{i}=u \mid Y\right]$ is estimated for $u=1,2, \ldots, N$, where the joint probability distribution is a multinomial with logistic regression on the independent variables $Y_{1}, Y_{2}, \ldots, Y_{p}$ :

$$
P\left[D_{i}=u \mid Y\right]=\frac{e^{\beta u Y u}}{1+\sum_{k=1}^{N-1} e^{\beta_{k} Y_{k}}} u=1,2, \ldots, N-1 ; P\left[D_{i}=N \mid Y\right]=\frac{1}{1+\sum_{k=1}^{N-1} e^{\beta_{k} Y_{k}}}(8)
$$

The marginal effect of the variable $\boldsymbol{Y}_{\boldsymbol{k}}$ on $P\left[D_{i}=u \mid Y\right]$ is defined as the variation in the conditional probability attributable to the explanatory variable $\boldsymbol{Y}_{k}, k=1,2, \ldots, p$. The set of estimates is calculated using the maximum likelihood function, while the goodness of fit test utilizes the root means square error and the pseudo-determination coefficient of McFadden (see Greene and Hensher 2013). For the calculations, we use the package "mlogit" R (https:// cran.r-project.org/web/packages/mlogit/index.html). Table 5 shows the results from applying

\begin{tabular}{|c|c|c|c|}
\hline \multirow[b]{2}{*}{ Year } & \multicolumn{3}{|c|}{ Poverty States } \\
\hline & 1 & 2 & 3 \\
\hline \multirow{2}{*}{1} & $0.116 \%$ & $0.585 \%$ & $-0.701 \%$ \\
\hline & $(1.68)^{*}$ & $(1.50)$ & $(-1.65)^{*}$ \\
\hline \multirow{2}{*}{2} & $0.090 \%$ & $0.742 \%$ & $-0.832 \%$ \\
\hline & $(0.16)$ & $(1.27)$ & $(-1.40)$ \\
\hline \multirow{2}{*}{3} & $1.167 \%$ & $0.514 \%$ & $-1.682 \%$ \\
\hline & $(3.39)^{*}$ & (1.53) & $(-4.19)^{* * *}$ \\
\hline
\end{tabular}
(8) to the estimated matrix of Table 4.

Table 5. Marginal effects of a variation in the GDP growth rate on the transition probabilities

Note: The probability estimations are based on 95\% confidence intervals. * Significant at 10 percent, *** significant at 1 percent. * 
Figures of Table 5 indicate that the probability of remaining in each state differs when the GDP growth rate increases by $1 \%$ : while that probability increases by $0.116 \%$ in state 1 , it decreases by $1.682 \%$ in state 3 . The marginal effects of a variation in GDP in the rest of the entries are more significant in state 3 than in state 1 , as we move from left to right. In state 2, there is no statistically significant change. These results agree with those of Table 2 since families of states 1 and 3 react more favorably to GDP changes during the entire period.

After incorporating those marginal effects into the estimated transition probabilities of Table 4, one obtains the new estimated probabilities adjusted for the GDP growth rate. The right part of that Table 6 shows that the adjustment only benefits the families of states 1 and 3 . The transition probabilities of moderate poor are insensitive to variations in the GDP growth rate and maintain almost the same pattern as in Table 4. In general, all the entries have a similar distribution as the observed probabilities, which means that they also fit a Markov chain pattern, with a new p-value of 0.1368 (see the chi-square test at the bottom of Table 6).

Table 6. Transition probabilities adjusted for the GDP growth rate

\begin{tabular}{|c|c|c|c|c|c|c|c|}
\hline States & 1 & 2 & 3 & States & 1 & 2 & 3 \\
\hline & 0.2770 & 0.2101 & 0.5129 & & 0.2864 & 0.2143 & 0.4993 \\
\hline 1 & $\begin{array}{c}(0.1179 \\
0.4361)\end{array}$ & $\begin{array}{c}(0.0511, \\
0.3692)\end{array}$ & $\begin{array}{c}(0.3538 \\
0.6720)\end{array}$ & 1 & $\begin{array}{c}(0.1355, \\
0.4261)\end{array}$ & $\begin{array}{c}(0.0648, \\
0.3554)\end{array}$ & $\begin{array}{l}(0.3443, \\
0.6349)\end{array}$ \\
\hline & 0.3438 & 0.2793 & 0.3769 & & 0.3438 & 0.2793 & 0.3769 \\
\hline 2 & $\begin{array}{c}(0.2340 \\
0.3936)\end{array}$ & $\begin{array}{c}(0.2295, \\
0.3288)\end{array}$ & $\begin{array}{c}(0.3273 \\
0.4265)\end{array}$ & 2 & $\begin{array}{c}(0.2942, \\
0.3935)\end{array}$ & $\begin{array}{c}(0.2296 \\
0.3289)\end{array}$ & $\begin{array}{c}(0.3272, \\
0.4265)\end{array}$ \\
\hline & 0.2974 & 0.2145 & 0.4881 & & 0.3363 & 0.2145 & 0.4320 \\
\hline 3 & $\begin{array}{c}(0.1571 \\
0.4378)\end{array}$ & $\begin{array}{c}(0.0742, \\
0.3548)\end{array}$ & $\begin{array}{c}(0.3481 \\
0.6286)\end{array}$ & 3 & $\begin{array}{c}(0.1261, \\
0.4011)\end{array}$ & $\begin{array}{c}(0.1156 \\
0.3822)\end{array}$ & $\begin{array}{c}(0.3542, \\
0.6292)\end{array}$ \\
\hline
\end{tabular}

\section{Stationary probabilities}

An essential feature of the Markov matrices is the behavior of their long-term transition probabilities, known as stationary probabilities. They offer valuable information about the SD dynamics' limit values, which shed light on the final conditions of each state's population's deprivation. However, the procedure to estimate them is not always straightforward since it requires learning about the Markov chain's ergodicity properties. 
Specifically, if we carefully observe the matrices on the left side of Tables 4 and 6 , we realize that states communicate with each other, as there is always a way to reach a fixed state $\boldsymbol{s}_{\boldsymbol{j}}$ from any other state $\boldsymbol{s}_{i}$. This communicative characteristic implies that the states of the matrix make up a closed set $\boldsymbol{C}$ so that $\sum_{j \in C} P(i, j)=1$ for each $i \in C$ and, consequently, they form an irreducible set. With closed and finite sets, the states are recurrent and constitute a final class where the states' communication is such that if the chain were to arrive at one of these states, it would evolve within the same class's states the next transitions.

Matrices with these types of states are regular and ergodic as the stationary values are independent of the original state, and there are no null values in any of the entries of the steadystate matrix. For these matrices, equation (5) provides the procedure to calculate the ergodic vectors. This equation yields steady-state probabilities that are equivalent to those resulting from exponentiating the Markov matrix $\boldsymbol{n}$ times (or $\boldsymbol{n}$ steps), as stated by the equation of Chapman-Kolmogorov:

$$
\operatorname{Pr}\left(X_{n}=s_{j} \mid X_{0}=s_{i}\right)=P^{n}\left(s_{i}, s_{j}\right)(9)
$$

Tables 7 and 8 show the results from the calculation of (5) for matrices, including adjusted and unadjusted probabilities $\gamma_{i j}$ for GDP growth. Every Table contains the stationary transition probabilities for the five regions and two additional columns: one for the Likelihood Ratio (LR) statistic associated with a log-linear model and the other for $\boldsymbol{p}$ values to accept or reject the null hypothesis of convergence of the observed matrices. Figures in both Tables show that, although the matrices without adjustments reject the null hypothesis of stationarity because they violate the log-linear model (with $\boldsymbol{p}=0$ values), matrices with GDP growth adjustments do not. This result means that the adjusted matrices represent the ergodic vectors of the observed matrices (for a better understanding of the LR statistic, see Fingleton 1997). Rows of these matrices are the ergodic vector for the country and the regions resulting from the estimation of (5) and constitute the limit probabilities of (9) after iterating the Markov matrix eight times (32 years).

Table 7. Steady-state probabilities without adjustment for GDP growth by Region

\begin{tabular}{|c|c|c|c|c|c|}
\hline & & States & & & \\
\hline & 1 & 2 & 3 & LR Statistic & pvalue \\
\hline Country & 0.3018 & 0.2279 & 0.4703 & 159.33 & 0.0000 \\
\hline Region 1 & 0.3379 & 0.2411 & 0.4210 & 161.62 & 0.0000 \\
\hline Region 2 & 0.2787 & 0.2344 & 0.4869 & 79.58 & 0.0000 \\
\hline Region 3 & 0.3074 & 0.2555 & 0.4371 & 202.70 & 0.0000 \\
\hline Region 4 & 0.3580 & 0.2906 & 0.3513 & 168.77 & 0.0000 \\
\hline Region 5 & 0.3870 & 0.1800 & 0.4330 & 32.20 & 0.0000 \\
\hline
\end{tabular}


Table 8. Steady-state probabilities with adjustment for GDP growth by Region

\begin{tabular}{|c|c|c|c|c|c|}
\hline & & States & & & \\
\hline & 1 & 2 & 3 & LR Statistic & pvalue \\
\hline Country & 0.2790 & 0.2027 & 0.5183 & 1.324 & 0.1289 \\
\hline Region 1 & 0.2773 & 0.1750 & 0.5478 & 1.311 & 0.1175 \\
\hline Region 2 & 0.2563 & 0.2084 & 0.5353 & 1.585 & 0.1063 \\
\hline Region 3 & 0.3035 & 0.2485 & 0.4479 & 1.458 & 0.1171 \\
\hline Region 4 & 0.3441 & 0.2735 & 0.3824 & 3.663 & 0.1388 \\
\hline Region 5 & 0.3698 & 0.1579 & 0.4723 & 0.682 & 0.1010 \\
\hline
\end{tabular}

Source: Authors.

According to the ergodic vectors (Table 8), the poor will suffer a slight deterioration of their social living conditions over the next eight periods (32 years), given a stable GDP growth rate scenario. The probability of remaining as moderate poor will decrease from 0.2793 to 0.2027 while remaining extreme poor will increase from 0.4320 to 0.5183 . The lacking population will not experience any change at all. This situation will become worst in less economically developed regions. For instance, regions I and 2 have a steady-state probability of remaining in state 3 above the national average $(54.78 \%$ and $53.53 \%$, respectively) and a lower probability of remaining in state 1 than Mexico's most advantaged regions (3, 4, and 5). So, the future situation for these regions may worsen.

\section{The hidden Markov models as a complementary approach}

The previous results establish that Mexico's transition probabilities follow a one-step Markov chain, which is also regular and ergodic. These characteristics back the assumptions needed by the HMM to perform correctly.

This approach's application becomes especially useful to confirm the Markov matrices' optimal size and deepen the meaning of the ergodic values calculated in section 4 . Both activities make the entire analysis more robust. Table 9 shows the optimal matrix size when the process parameter is a binomial distribution, and the EM algorithm endogenously determines the number of states after maximizing the likelihood function (7). The Table shows that the $3 \times 3$ matrix is optimal because it records the lowest values of the Akaike information criteria (AIC) and the Bayesian information criteria (BIC), which means that different sizes of matrices weaken the Markovian pattern as they can break communication links between states. This result supports the previous analysis based on observable Markov matrices.

Table 9. The optimal size of states according to the Hidden Markov Model

\begin{tabular}{ccccc}
\hline $\begin{array}{c}\text { Probability } \\
\text { Distribution }\end{array}$ & $\begin{array}{c}\text { Number of } \\
\text { States }\end{array}$ & $\begin{array}{c}\text { Log- } \\
\text { likelihood }\end{array}$ & AIC & BIC \\
\hline & 2 & $-10,023.54$ & $20,089.1$ & $20,230.2$ \\
\multirow{2}{*}{ Binomial } & 3 & $-9,388.23$ & $18,846.5$ & $19,081.6$ \\
& 4 & $-11,039.76$ & $20,149.1$ & $20,491.7$ \\
\hline
\end{tabular}


Similarly, the calculation of hidden state-dependent matrices $\Pi$ helps complement the conclusions reached with direct Markov matrices $\Gamma$. Table 10 shows that though both matrices present different states' patterns, their ergodic values $\delta$ confirm the same situation described in Table 6: the long-term probability of remaining extremely poor is the highest. In particular, the second to last column of that Table makes it clear that the mean of events is lower (and with more significant dispersion) in state 1 than in the other two states, indicating that the state-dependent probabilities obtained from (6) are more likely to follow a pattern like the one described by the sate 3 than by the rest of states.

Table 10. Estimates of the parameters of the Hidden Markov Model using the Expectation-Maximization algorithm

\begin{tabular}{cccccc}
\hline States & $\mathbf{1}$ & $\mathbf{2}$ & $\mathbf{3}$ & Mean & $\begin{array}{c}\text { Standard } \\
\text { Deviation }\end{array}$ \\
\hline & & & & & \\
1 & 0.402 & 0.357 & 0.241 & 2.514 & 0.942 \\
2 & 0.330 & 0.206 & 0.464 & 2.845 & 1.102 \\
3 & 0.227 & 0.290 & 0.483 & 4.139 & 1.073 \\
& & & & & \\
\hline & & & & & \\
\cline { 2 - 4 } & & & & & \\
\hline
\end{tabular}

Source: Authors.

The most pressing deprivals explaining these dynamics are nutrition and child mortality, as displayed in Tables $11 \mathrm{a}$ and $1 \mathrm{lb}$. Following the results of a multi-logit model for each state, in which deprivals are now the independent variables, Table $11 \mathrm{~b}$ shows that both deprivals' marginal effects on the state-dependent probabilities are the most decisive of all. A marginal 1\% increase in child mortality, for example, decreases the probability of remaining in state 1 by 11 . $26 \%$, but significantly increases their probability of migrating to the most disadvantaged states $(10.25 \%$ and $5.21 \%$ to states 2 and 3 , respectively). In the case of nutrition, its impact grows as we move from left to right. A family experiencing nutrition problems increases its probability of remaining moderately poor by $13.69 \%$ and $18.85 \%$ of becoming extremely poor. Table $11 \mathrm{a}$ highlights the signs of the deprival coefficients that are most determinant in each transition by states (for the calculations, we use the "mlogit" R package: https://cran.r-project.org/web/ packages/mlogit/mlogit.pdf ).

The fact that infant mortality and nutrition are the main deprivals is very significant. They are associated with a long-term project of social exclusion. The families that suffer from starvation or their children's death belong to the Mexican group that permanently experiences exclusion from the country's economic progress - its precariousness results from a flawed GDP distribution system and other problems discussed in the next section. 
Table 11a. Main deprivations affecting the state-dependent transition probabilities

\begin{tabular}{cccc}
\hline & $\mathbf{1}$ & $\mathbf{2}$ & $\mathbf{3}$ \\
\hline $\mathbf{1}$ & Child Mortality & Child Mortality & Nutrition \\
& $(-)$ & $(+)$ & $(+)$ \\
$\mathbf{2}$ & Years of Schooling & Nutrition & Nutrition \\
& $(-)$ & $(+)$ & $(+)$ \\
& Nutrition & Years of Schooling & Child Mortality \\
& $(-)$ & $(-)$ & $(+)$ \\
\hline
\end{tabular}

Note: signs between round brackets indicate the direction of the relationship between deprivations and statedependent probabilities.

Source: Authors.

Table 11b. Marginal effects of a variation in deprivation levels on the state-dependent probabilities

\begin{tabular}{|c|c|c|c|c|c|c|c|c|c|}
\hline & $\pi \mathbf{1 1}$ & $\pi 12$ & $\pi \mathbf{1 3}$ & $\pi 21$ & $\pi 22$ & $\pi 23$ & $\pi 31$ & $\pi 32$ & $\pi 33$ \\
\hline \multirow{2}{*}{ Years of Schooling } & -0.0729 & 0.0004 & 0.0832 & -0.0683 & 0.0532 & 0.0916 & -0.0508 & -0.1232 & 0.0486 \\
\hline & $(-3.29)^{* * * *}$ & $(1.09)$ & $(3.29) * * *$ & $(-3.35)^{* * *}$ & $(4.35)^{* * *}$ & $(3.54)^{* * * *}$ & $(-4.09) * * *$ & $(-2.97) * * * *$ & $(3.54)^{* * *}$ \\
\hline \multirow{2}{*}{$\begin{array}{l}\text { Child School } \\
\text { Attendance }\end{array}$} & -0.0430 & 0.0002 & 0.0436 & -0.0331 & 0.0243 & 0.0481 & -0.0266 & -0.0543 & 0.0243 \\
\hline & $(-2.83)^{* * * *}$ & $(1.34)$ & $(3.29) * * *$ & $(-3.04) * * *$ & $(2.97)^{* * *}$ & $(3.12)^{* * * *}$ & $(-4.09) * * *$ & $(-4.31) * * *$ & $(3.06)^{* * *}$ \\
\hline \multirow{2}{*}{ Child Mortality } & -0.1126 & 0.1025 & 0.0521 & -0.0209 & 0.1063 & 0.0698 & -0.0924 & -0.1116 & 0.1242 \\
\hline & $(-3.87)^{* * * *}$ & $(2.71)^{* * * *}$ & $(2.65)^{* * * *}$ & $(-1.75)^{*}$ & $(2.65)^{* * * *}$ & $(3.32)^{* * *}$ & $(7.34) * * *$ & $(-2.73)^{* * * *}$ & $(2.78)^{* * * *}$ \\
\hline \multirow{2}{*}{ Nutrition } & -0.0182 & 0.0335 & 0.1016 & -0.0518 & 0.1369 & 0.1885 & -0.1439 & -0.0897 & 0.0068 \\
\hline & $(-6.70)^{* * * *}$ & $(1.97)^{* * * *}$ & $(2.29) * * *$ & $(-1.98) * * *$ & $(2.12)^{* * * *}$ & $(2.23) * * *$ & $(2.37)^{* * * *}$ & $(3.04)^{* * * *}$ & $(1.43)$ \\
\hline \multirow{2}{*}{ Electricity } & -0.0312 & 0.0309 & 0.0204 & -0.0084 & 0.0153 & 0.0498 & -0.0153 & -0.0231 & -0.0144 \\
\hline & $(-2.93)^{* * * *}$ & $(2.06)^{* *}$ & $(2.34)^{* * *}$ & $(-0.13)$ & $(1.71)^{*}$ & $(4.37)^{* * * *}$ & $(1.77)^{*}$ & $(2.85)^{* * *}$ & $(-0.21)$ \\
\hline \multirow{2}{*}{ Improved Sanitation } & -0.0072 & -0.0005 & 0.0396 & -0.0361 & 0.0307 & 0.0521 & -0.0326 & -0.0243 & 0.0333 \\
\hline & $(-3.18)^{* *}$ & $(-0.18)$ & $(7.81) * * *$ & $(-5.62) * * * *$ & $(7.02)^{* * * *}$ & $(5.46)^{* * *}$ & $(4.82)^{* * * *}$ & $(7.08)^{* * *}$ & $(2.54)^{* * *}$ \\
\hline \multirow{2}{*}{ Safe Drinking Water } & -0.0251 & 0.0147 & 0.0231 & -0.0520 & 0.0391 & 0.0852 & -0.0404 & -0.0148 & 0.0560 \\
\hline & $(-4.78)^{* * * *}$ & $(1.69)^{*}$ & $(4.23)^{* * *}$ & $(-4.23)^{* * * *}$ & $(4.34)^{* * * *}$ & $(3.93)^{* * *}$ & $(-4.54)^{* * * *}$ & $(-2.46)^{* *}$ & $(4.38)^{* * * *}$ \\
\hline \multirow{2}{*}{ Flooring } & -0.0226 & 0.0052 & 0.0247 & -0.0288 & 0.0268 & 0.0200 & -0.0268 & -0.0340 & 0.0154 \\
\hline & $(-5.45)^{* * * *}$ & $(1.42)$ & $(5.67)^{* * * *}$ & $(-3.67)^{* * * *}$ & $(6.23)^{* * * *}$ & $(4.08)^{* * * *}$ & $(-3.75)^{* * * *}$ & $(-2.10)^{* * * *}$ & $(2.03)^{* * *}$ \\
\hline \multirow{2}{*}{ Cooking Fuel } & -0.0143 & 0.0176 & 0.0234 & -0.0165 & 0.0241 & 0.0123 & -0.0218 & -0.0236 & -0.0011 \\
\hline & $(-6.15)^{* * *}$ & $(3.21)^{* * * *}$ & $(7.35)^{* * * *}$ & $(-2.34) * * *$ & $(2.27)^{* * * *}$ & $(2.03)^{* * * *}$ & $(-6.34)^{* * * *}$ & $(-6.78)^{* * * *}$ & $(-0.12)$ \\
\hline \multirow{2}{*}{ Asset Ownership } & -0.0261 & 0.0130 & 0.0109 & -0.0633 & 0.0022 & 0.0378 & -0.0022 & -0.0529 & 0.0523 \\
\hline & $(-3.14)^{* * * *}$ & $(5.12)^{* * *}$ & $(2.83)^{* * * *}$ & $(-3.58)^{* * * *}$ & $(0.24)$ & $(6.41)^{* * *}$ & $(0.34)$ & $(2.77)^{* * * *}$ & $(5.12)^{* * *}$ \\
\hline
\end{tabular}

Note: The probability estimations are based on 95\% confidence intervals. * Significant at 10 percent, **significant at 5 percent $* * *$ significant at 1 percent. 


\section{Discussion}

The preceding statistical analyses appear pessimistic, considering research explaining how Mexico's population can escape poverty. Unlike the studies by Cárdenas and Luna (2006) and Lobato (2015), the ergodic vectors calculated here present a country permanently dealing with deprivation.

Is this scenario realistic? The simple answer is that with transition matrices extracted from ENNVIH, better stationary probabilities are unlikely to be expected. This survey does not allow estimating a state of zero deprivation, so there is no way to visualize a more robust probabilistic scenario for families escaping impoverishment. The paper concentrates on analyzing the probabilities of exposure to deprivation of people who are already deprived. For this reason, the ergodic vectors of Tables 8 and 10 may be showing only a part of the whole poverty process in Mexico.

The validity of the stationary probabilities for the entire country depends on how closely communicated the states of deprivation and non-deprivation are. If both types of states do not communicate with each other (or are mutually absorbing), those probabilities can be considered realistic, meaning that moderately poor are more likely to be extremely poor soon. On the contrary, if deprivation and non-deprivation states are not absorbing, we must qualify the meaning of the stationary probabilities. For instance, Corona (2021) holds that the top four deciles of Mexico's income distribution form an absorbing state, as their economic position remains practically unchanged over time. While this type of conclusion backs our results, we cannot give a complete answer for sure. Instead, we prefer to offer two qualitative reasons to ensure that the ergodic vector results are robust due to non-existent communication between the two kinds of states. We refer to the historic combination of low GDP growth rates and income inequality and the inconclusive results of Mexico's poverty reduction programs.

Regarding the first reason, it is crucial to consider that during the last fifty years, Mexico's GDP growth rates have registered a steady decrease from 4.21\% (between 1950 and 1988) to 2.06\% (between 2017 and 2018), which has caused the national per-capita income to grow at a slower rate than the population in 13 years (Chiquiar and Ramos 2009; INEGI several years). This fall's consequences have been reflected in the widening of the gap between the rich and the poor, whether people or regions, mainly because successful growth has tended to concentrate in specific areas (Chiquiar, 2005; Cermeño et al., 2009). Not surprisingly, Mexico's economic growth has not been listed as pro-poor, especially between 2005 and 2014. Except for two entities that experienced pro-poor net growth, GDP changes have only negatively affected the inhabitants' welfare (Campos and Monroy, 2016).

Additionally, institutional (caciques, non-market organizations), cultural (non-commercial survival strategies), political, and even religious factors prevent the poor from gaining access to the benefits of economic progress in the country. These factors' influence reinforces income inequality and explains why $50 \%$ of rural municipalities, or $8.3 \%$ of the Mexican population, experience poverty traps in food and property (Pereira and Soloaga, 2015). The interactions between those non-economic factors and SD are so close that there is no justification for ensuring an automatic link between GDP growth and poverty alleviation. Increases in GDP growth rates are not enough to free from deprivation, especially when their transition probabilities proved to be insensitive to GDP changes for moderate poor, at least for the 2002-2012 period (see Table 5). Therefore, GDP growth is a necessary but not sufficient condition to alleviate poverty. The economic and non-economic factors explaining income inequality matter, as they can reduce the positive, decreasing impact of economic growth upon poverty (Ravallion 2007). Countries, like Mexico, with high initial income inequality, tend to grow less and share most of the distributional gains from growth among the richest (Iniguez 2014). 
As far as the second reason is concerned, we say that the government's anti-poverty results are inconclusive because the money transfer or social security programs are the only ones in operation. Except for these short-run welfare policies, the country does not have a systematic and integrated plan to reduce poverty ( $\underline{\mathrm{Scott} 2004})$. The declining performance of the entire economy and the absence of a defined strategy to promote activities in favor of the poor, such as textile or food industries in marginalized zones, minimize the beneficial impact of the social assistance programs (Cazzuffi et al. 2017). These programs' contribution is marginal and temporary, as shown by Progresa, Mexico's flagship anti-poverty social assistance program since 1997, renamed as Oportunidades in 2001 and then as Prospera in 2010 (Scott 2004). Despite the extensive coverage of this program, which by the end of 2015 already supported 6.1 million households in poverty or $25 \%$ of the Mexican population, it was only able to reduce poverty by less than one percentage point in a few years between 2000 and 2012 (Bracamontes and Camberos 2015; Masino and Niño-Zarazúa 2020).

Under such circumstances, it is not likely to foresee an intense exchange or communication between deprived and non-deprived states shortly. Without sustained economic growth, it is impossible to finance public services that improve education in the long term. Similarly, promoting social programs without favorable economic growth rates means superficially overcoming poor nutrition or low life expectancy at birth. These statements are critical because reducing deprivals related to years of schooling, poor nutrition, and child mortality significantly increases the state-dependent probabilities of moving from more deprived states to less deprived states. Table $11 \mathrm{~b}$ shows, for example, that a reduction of $1 \%$ in poor nutrition increases the probability of going from state 3 to states 1 and 2 by $8.97 \%$ and $14.39 \%$, respectively.

The point is that reducing the number of these deprivals requires maintaining minimum growth rates of GDP to absorb the incoming workforce and, at the same time, adopting economic pro-poor economic strategies to hire the unemployed marginal population. Only in this way does it make sense to establish redistributive income mechanisms through social assistance programs. Mexico's government must formulate a new institutional arrangement between key agents in some country zones to unlock the structural lags that prevent the poor from accessing economic growth benefits. In this process, both agents and the government must implement democratic policies to achieve the best possible decentralization of the poverty relief function at the municipality level (Hernandez-Trillo 2016). Otherwise, deprived and non-deprived states will continue to remain separate, and the scenario described by these Markov models would become increasingly real.

\section{Conclusions}

This document supports the idea that SD in Mexico follow a one-step Markov chain pattern. Different tests on the dynamic evolution of SD show that transition probabilities matrices, especially those adjusted for GDP, are regular and ergodic, allowing applying HHM to confirm the dynamic pattern of deprivation.

The statistical analysis confirms that the optimal number of three states behave consistently over time, whether we use direct or hidden Markov chains. Results show that the most deprived states' transition probabilities are insensitive to GDP growth rates (direct method) and have the most considerable means of occurrence (hidden method). Consequently, the matrices' ergodic values show a higher long-term probability of remaining extremely poor. In any case, nutrition and child mortality are the two most significant deprivals that affect those stationary probabilities.

The whole analysis concludes that poor Mexicans are more likely to remain poor by experiencing progressively more deprivals than staying in states with fewer deprivals. In the absence of significant GDP growth rates or income distribution mechanisms that allow people to benefit 
from such changes, it is impossible to expect a more favorable scenario, as suggested by several studies dealing with the exit from poverty in Mexico.

\section{References}

Alkire, S., Kanagaratnam, U., and Suppa, N. (2020). The global Multidimensional Poverty Index (MPI): 2020 revision', OPHI MPI Methodological Note 49, Oxford Poverty and Human Development Initiative, University of Oxford. https://ophi.org.uk/multidimensional-poverty-index/

Arranz J, Cantó O (2012). Measuring the effect of spell recurrence on poverty dynamics. Journal of Economic Inequality 10(2):191-217.

Ayllón S (2013). Understanding poverty persistence in Spain. SERIEs 4: 201-233.

Bracamontes N, Camberos M (2015). La incidencia de pobreza e impacto del programa Oportunidades en el país y el Estado de México. Economía Informa, 393: 21-33.

Campos R, Monroy G (2016). ¿El crecimiento económico reduce la pobreza en México? Revista de Economía Mexicana, 1:140-185.

Cárdenas R, Luna L (2006). Estimación del Tiempo de Salida de la Pobreza: Una Aplicación a los Diez Municipios más Marginados de México. Estudios Económicos, 21 (1):45-54.

Cazzuffi C, Pereira M, Soloaga I (2017). Local poverty reduction in Chile and Mexico: The role of food manufacturing growth. Food Policy 68:160-185.

Cermeño R, Mayer D, Martínez A (2009). Convergencia, divergencia y estratificación. Estudio comparativo de la dinámica de crecimiento de la manufactura en los municipios mexicanos y los condados estadounidenses. El Trimestre Económico, 76(302):349-378.

Chiquiar D (2005). Why Mexico's regional income convergence broke down. Journal of Development Economics. 77(1):257-275.

Chiquiar D, Ramos M. (2009). Competitiveness and Growth of the Mexican Economy. Banco de Mexico, Working Papers 11, Mexico City.

CONEVAL (2016). Medición de la pobreza 2008-2016. http://www.coneval.org.mx/Medicion/Paginas/AE pobreza 2008-2016.aspx.

Corona, S. (2021). Las privaciones sociales en México como causa del deterioro del bienestar de los hogares. Tesis de Doctorado, IPN.

Dotto F, Farcomeni A, Grazi M, Zelli R (2018). A dynamic inhomogeneous latent state model for measuring material deprivation. Journal of the Royal Statistical Society. Series A:1-22.

Feldman R, Valdez C (1996). Applied Probability and Stochastic Processes, Publishing Company, Boston, MA.

Fingleton B (1997). Specification and Testing of Markov Chain Models: an Application to Convergence in the European Union. Oxford Bulletin of Economics and Statistics, 59(3):385-403.

Greene W, Hensher D (2013). Revealing Additional Dimensions of Preference Hetero geneity in a Latent Class Mixed Multinomial Logit Model. Applied Economics, 45(14):1897-1902.

Hernández-Trillo F (2016). Poverty alleviation in federal systems: The case of Mexico. World Development, 87: 204-214.

INEGI (several years). PIB y Cuentas Nacionales. https://www.inegi.org.mx/temas/pib/

Iniguez, M (2014). Growth with equity for the development of Mexico: Poverty, Inequality, and Economic Growth (1992-2008). World Development, 59:313-326. 
Lee TG, Judge GG, Zellner A (1970). Estimating the Parameters of the Markov Probability Model from Aggregate Time Series Data, North-Holland Publishing Company, Amsterdam, London.

Lobato M (2015). Tiempo de salida de la pobreza en áreas urbanas y rurales de México. Frontera Norte, 27(54):99-122.

Mac Donald I, Zucchini W (1997). Hidden Markov and Other Models for Discrete valued Time Series, 1st ed. Chapman \& Hall, Boca Raton, FL.

Masino S, Niño-Zarazúa M (2020). Improving financial inclusion through the delivery of cash transfer programmes: The case of Mexico's Progresa-Oportunidades Prospera Programme. The Journal of Development Studies, 56(1): 151-168.

Najera H (2017). Multiple deprivation, severity, and latent sub-groups: advantages of factor mixture modelling for analysing material deprivation. Social Indicators Research,131:681-700.

Oxford Poverty and Human Development Initiative (OPHI) (2015). Multidimensional Poverty Index 2015. OPHI Briefing 29, University of Oxford.

Pelzer B (2001). Estimating transition probabilities from a time series of independent cross sections. Statistica Neerlandica, 55(2): 249-262.

Pereira M, Soloaga I (2015). Trampas de pobreza y desigualdad en México: 1990-2010, in Bebbington A, Escobar J, Soloaga I, Tomaselli S, Trampas Territoriales de Pobreza, Desigualdad y Baja Movilidad Social: Los Casos de México, Chile y Perú. Centro de Estudios Espinoza Iglesias y Universidad Iberoamericana. México, 167-230.

Ravallion M (2007). Economic growth and poverty reduction: Do poor countries need to worry about inequality? 2020 focus brief on the world's poor and hungry people. Washington, DG: IFPRI.

Rubalcava L, Teruel G (2013). Mexican Family Life Survey. Third Wave. Working Paper. www. ennvih-mxfls.org

Scott J (2004). La descentralización, el gasto social y la pobreza en México. Gestión y Política Pública, 13 (3): 785-831.

Székely, M, Ortega D (2014). Pobreza Alimentaria y Desarrollo en México. El Trimestre Económico, 81(321):43-105.

UIA, CIDE, Duke University (2016). Encuesta Nacional sobre Niveles de Vida de los Hogares (ENNVIH). http://www.ennvih-mxfls.org/english/index.html

Watson D, Maître B, Whelan C, Russell H (2017). Poverty, economic stress, and quality of life: lessons from the Irish case. International Review of Economics, 64:125-143.

Weisberg H (1986). Central tendency and variability. Newbury Park. Sage.

Whelan C, Maitre B (2006). Comparing poverty and deprivation dynamics: issues of reliability and validity. Journal of Economic Inequality, 4(3):303-323.

Whelan C, Maitre B (2007). Measuring material deprivation with EU SILC: Lessons from the Irish survey. European Societies, 9 (2):147-173.

Sen A (1981). Poverty and famines: Essay on entitlement and deprivation. Oxford Clarendon. 